IBIMA Publishing

Journal of Southeast Asian Research

http://ibimapublishing.com/articles/JSAR /2021/747009/

Vol. 2021 (2021), Article ID 747009, 15 pages, ISSEN: 2166-0832

DOI: $10.5171 / 2021.747009$

Research Article

\title{
Sustainability in Health Service Industry: The Implementation of Material Flow Cost Accounting (MFCA) as an Eco-Efficient Analysis
}

\author{
Dianwicaksih ARIEFTIARA, Ria Maria THERESA \\ And Retna SARI \\ Universitas Pembangunan Nasional Veteran Jakarta, Jakarta, Indonesia \\ Correspondence should be addressed to: Dianwicaksih ARIEFTIARA; dianwicaksih@upnvj.ac.id \\ Received date:27 November 2020; Accepted date: 21 January 2021; Published date:13 July 2021 \\ Academic Editor: Ainon Ramli \\ Copyright (C) 2021. Dianwicaksih ARIEFTIARA, Ria Maria THERESA and Retna SARI. Distributed under \\ Creative Commons Attribution 4.0 International CC-BY 4.0
}

\begin{abstract}
This research intends to analyze the level of efficiency at hospitals to increase the efficiency of productivity and industrial competitiveness, and to support the government's commitment regarding the Sustainability Development Goals program. This research performed a productivity analysis using Material Flow Cost Accounting (MFCA) which is divided into several stages, namely the planning stage (Plan), the second stage of implementation (Do), the third stage of evaluation (Check), and the last is the follow-up stage (Act). The analysis focuses on financial and operational reporting data for three months, and showed that the current efficiency level of Hospital X was $68.54 \%$, indicating a high level of efficiency of the hospital. However, with the conventional method, the hospital was yet unable to identify the level of inefficiency related to the environment or pollution caused by the hospital's operational activities. The implementation of MFCA resulted in the fact that the hospital's operational activities for three months have consequences in $9 \%$ of the negative products from the total material input or at amount of Rp. 12,516,456, which was previously unobserved by conventional methods. The results of the material flow tracing using MFCA have key benefits, such as minimizing waste, thereby saving the environment from damage, and thus realizing the sustainable operation of hospital X. This means that if MFCA is applied continuously in Hospital X, it will not only save expenses but can also achieve eco-efficiency and realize continuous improvements so that, in the long-term, operational sustainability can be achieved.
\end{abstract}

Keywords: Material Flow Cost Accounting; Productivity Efficiency; Material Loss, Hospital

\section{Introduction}

Indonesia as a member of the G20 is committed to supporting and achieving the
SDGs, which are the global development agenda for the period (2016-2030). In line with Indonesia's commitment to the SDGs, Material Flow Cost Accounting (MFCA) is a

Cite this Article as: Dianwicaksih ARIEFTIARA, Ria Maria THERESA and Retna SARI (2021), "Sustainability in Health Service Industry: The Implementation of Material Flow Cost Accounting (MFCA) as an EcoEfficient Analysis", Journal of Southeast Asian Research, Vol. 2021 (2021), Article ID 747009,

DOI: $10.5171 / 2021.747009$ 
technique to calculate material loss or "waste". In the current production process, companies, generally, focus only on the output that was produced, which will be transferred to the next processor to consumers. Waste/material losses at MFCA are all materials (inputs) that are wasted and do not enter the output of a production process (both goods and services). The productivity improvement program through MFCA is relatively new and has not been widely or generally known by businesses and institutions in various regions in Indonesia, especially in the health service industry.

Several previous studies regarding the implementation of MFCA were generally conducted on manufacturing companies in Indonesia and around the world, such as Western, Asia-Pacific Countries (Christ \& Burritt, 2016; Darkamin \& Barmaki, 2019; Tajelawi \& Gharbarran, 2015; Ichimura \& Takakuwa, 2013). Literature has documented that MFCA is a valuable indicator of the company's potential growth and environmental impact. Substantial companies that implement MFCA could recognize losses (waste) that were previously unnoticed. Some of the research evidence suggests that MFCA can improve decision-making procedures and increase profitability. The MFCA method is different from the traditional manufacturing cost of production system that allows companies to trace their inventory efficiency by controlling material wastes. There is still very limited research on eco-efficiency, especially in the health service industry. This is why it is necessary to conduct research analysis using MFCA, considering the benefits it will have towards improving the health services (hospitals).

Hospitals are service providers in the health sector. In their business processes, a lot of materials are needed as inputs, and hospitals consume various resources to support health services. Hospitals allocate a large source of funds in investing in medical equipment, buildings, and providing other supporting facilities. These various tools, buildings, and facilities require resources to function properly such as electricity, water, as well as other supporting materials that require certain specifications (medical supplies such as gloves, masks, syringes, alcohol, bandages, gauze, etc.). In addition, they also require large maintenance costs as well as operational costs.

Most of the operational costs are fixed costs, while hospitals' income is a variable component whose amount cannot be determined certainly each month. As far as this research is concerned, the large operational costs of a hospital increase the medical expenses for both outpatients and inpatients. In addition, if it is indicated that the capacity of hospital facilities is not used optimally, the hospital's wastes on medical supplies as well as water and electricity resources can have negative impacts on the hospital, both monetary and non-monetary (negative impact on environmental sustainability).

There is an urgent need to find solutions for hospitals efficiency practices/procedures/strategies, in order to help reduce operational costs in which will eventually help realize the SDGs, namely health and welfare; life on land and under the sea; and sustainability of the city, environment and surrounding communities.

This research focuses on solving inefficiency problems in hospitals, analyzing the current level of efficiency in Hospital X, and identifying efforts to increase production efficiency through ecoefficient decisions using Material Flow Cost Accounting (MFCA) to improve economic and environmental performance, and achieve Sustainable Development Goals (SDGs). This research is expected to contribute in three ways. Firstly, this research is expected to contribute to establishing an in depth understanding of the MFCA concept and the implementation literature. It will add empirical evidence regarding the application of MFCA in the health service sector, particularly in hospitals.. This research is also expected to contribute to adding alternative accounting methods in calculating environmental costs. Moreover, it is also expected to provide empirical evidence of the benefits of MFCA in supporting environmental sustainability and increasing efficiency, productivity, and company performance. 
Secondly, this research can be considered as input and evaluation of the ongoing production process, in order to identify, reduce, and manage waste/material loss, as well as to increase the efficiency and productivity of the company. The results of this research are expected to support management to understand the mechanism of MFCA.

Thirdly, the results of this research contribute also to enlarging the scope of the Indonesian government's program in realizing its commitment to the Sustainable Development Goals (SDGs) in general, and the Ministry of Manpower's program in particular, namely an increase in productivity.

Finally, the results of this research are expected to contribute to the reduction in costs that must be borne by the community to enjoy health facilities. Using MFCA, costs are expected to reduce, and efficiency as well as productivity, are expected to increase. Hence, companies will no longer impose wastes or material losses on end consumers, which will eventually lower prices and make such services more affordable for them. This research adds empirical evidence on the implementation of MFCA in the Health services industry, particularly in hospitals, since MFCA is a new method and has a very limited implementation in Indonesia.

\section{Literature Review}

\section{Resource-Based Theory}

In the literature on management accounting, regarding company strategy, there are at least two resource-based theories. The first is the Resource-Based View (RBV), which explains that a company's competitive advantage can be a superior performance, through identifying its key resources with characteristics capable of producing excellence (Advantage-creating), such as value; scarcity; inability to be imitated (inimitability) or substituted; durability and appropriateness; as well as excellence in competitiveness (Barney, 1991).
The RBV theory argues that ownership and the identification of key resources under its control can create a sustainable competitive advantage for companies, through the development and distribution of products or services that have distinctive characteristics to consumers (Clulow et al., 2007). It can be briefly said that this theory links key resources to the Company's value for these resources. Several studies on the RBV aim to find empirical evidence of how consumers perceive the company's key resources (Clulow et al., 2007).

Another theory regarding company resources is, the Resource Dependence Theory (RDT), which is closely related to the external environmental conditions faced by companies. According to the RDT theory (Pfeffer and Salancik, 1978), the company is in an environment that provides scarce and limited resources, which lead this company to be in high uncertainty. To overcome such uncertainty of resource scarcity conditions, this theory explains that the company tries to develop various relationships with business partners to control and ensure the availability of resources for the production/operational needs of the company.

This resource-based theory underlies the idea that companies need to pay attention to the level of material inputs (all materials and resources included in the production process) instead of only focusing on the output itself. With scarce and limited resources, companies need to increase efficiency and productivity to produce superior products in terms of both quality and price, compared to competitors. The resource-based theory is the most appropriate explanation for the importance of material loss/waste reduction activities, which is the focus of Material Flow Cost Accounting (MFCA).

\section{Environmental Management Accounting}

Management accounting is a branch of accounting that intends to provide information to managers as a basis for decision making. The attention of the global business world to environmental issues, in connection with the climate change on earth, has made science develop following 
ongoing social issues so that it could contribute to solving problems faced, especially in the business world. Environmental Management Accounting (EMA) is a manager's tool for calculating and managing, as well as, providing information in order to make decisions and accommodate company interests with concerns about the social and environmental impacts resulting from their business processes (Burritt et al., 2008). Environmental Management Accounting is a term used to describe the integration of physical environmental information into the management accounting system, involving various tools, physical or monetary; past or future-oriented; routinely produced or produced based on a special interest; and having a focus on both the short and long term (Christ and Burritt, 2015). Several researches focusing on environmental issues have begun to emerge in the field of environmental management accounting research since 1988; however, they are still small in number compared to other accounting fields (Qian et al., 2010; Madein and Sholihin, 2014).

The focus on climate change and attention to the impact of business processes on the environment are evidenced by the shift in the production management of various industries in the world. Starting from the 1970s after the second world war, the industry at that time was dominated by manufacturing processes that used nonrenewable fuels (fossil fuels) and a very rapidly developing mass production manufacturing industry (mass production), as well as production management using industrial engineering (relying on Technique). The next stage is the period between the 1970s and 1990s, when there was a surge in oil prices resulting in price competition. The production process at this time focused on the optimization style whose ultimate goal is to reduce production costs, produce as efficiently as possible, and apply lean production and cell production management. Next, a period of climate change or global warming on the earth has begun, with a decrease in the available natural resources. At this time, the focus of the attention of the business world is on environmentally friendly production processes. Production management has shifted to the concept of kaizen or process improvements in all fields, and has begun to implement energy saving and waste management strategies, reducing wastes to reduce adverse impacts on the environment through Material Flow Cost Accounting (MFCA), among other methods.

\section{Material Flow Cost Accounting}

Material Flow Cost Accounting (MFCA) is an accounting technique that calculates the amount of material loss or waste in detail in each cycle involving input, process, and output (Tachikawa, 2015; Christ and Burritt, 2015; Ministry of Manpower, 2015). The MFCA method was first developed in Germany and further refined through application in the company by experts in Japan. This MFCA allows companies to obtain more outputs with minimal wastes or losses of input materials, so it has a significant impact on cost reduction and quality improvement (Kemenaker, 2015; Tachikawa, 2015).

Tachikawa (2015) explains that MFCA has advantages because its application is not limited to certain types of industry and company size, but can be applied to any industrial scope and field. Through MFCA, companies will get three benefits: (1) reduce costs, because MFCA is able to reduce material loss/waste; (2) increase energy efficiency, to reduce CO2 levels, which is very beneficial for the environment; and (3) increase material efficiency, because MFCA is able to identify the production process per flow of material to output (Tachikawa, 2015). Christ and Burritt (2015) examined the role of scientific research in helping deepen the understanding of the current MFCA developments.

\section{Methodology}

\section{Research Approach}

This research uses mixed method approaches to solve research problems. A qualitative approach is used because this research was focused on a single object of research in collecting data. This method is also called the case research method. A quantitative analysis is also used in this research to prove that the implementation 
of MFCA brings productivity changes to the hospital compared to productivity before the implementation of MFCA.

\section{Types of Data and Data Collection Techniques}

The focus of this research is to analyze the increase in hospital efficiency and productivity through decisions related to the environment, by implementing MFCA in calculating the cost of basic services. The scope of this research is comprehensive and detailed in all areas of hospital operations involving input, process, and output.

This research uses primary and secondary data types. The secondary data of this research are:

1. Financial reports and reports related to hospital operational expenses.

2. Hospital Company Profile.

3. Hospital business processes, especially operational processes related to the business unit (dental clinic), are used as research objects.

Meanwhile, primary data and data collection techniques in this research include management commitment to service efficiency and the discussion of service processes and procedures in the agreed business unit, being the focus of the research.

This research is divided into two stages:

\section{a. Phase I: Planning Stage}

This stage includes several actions or activities, namely:

1. Determination of target products/services.

2. Determination of MFCA Limits and quantity centers.

3. Determination of the time period.

4. Efficiency analysis using Conventional Production Management (CPM):

1. Making a material calculation per quantity center.
2. Making the cost implication (attaching the real nominal number per quantity center according to actual data).

5. Developing a model of material flow per quantity center.

b. Phase II: Implementation Stage:

1. Identification of input and output based on material flow model per quantity center.

2. Determination of the tie compound.

3. Evaluating and filtering material balances.

4. Calculating the input-output in monetary units.

5. Making the cost implication (attaching the real nominal number to the quantity center according to the accrual data).

6. Calculating waste or loss (per unit and per rupiah).

7. Analysis and interpretation of MFCA results.

\section{Results and Discussion}

\section{Description of the Research Object}

This research was conducted at a private hospital located in Depok, West Java. According to the agreement with the hospital management, for the purposes of this research, the hospital's identity is kept secret. Hospital $\mathrm{X}$ is a relatively new hospital and is open to the public, serving various groups including Indonesian Insurance and Social Security participants (known as Badan Penyelenggara Jaminan Sosial -BPJS in Indonesian terms). The hospital is located on a land of +/- 2000 square meters and consists of 4 floors. The hospital's services and facilities are very complete, consisting of medical facilities in the form of dialysis; an Emergency Room (IGD); an Intensive Care Unit (ICU); a Neonatal Intensive Care Unit (NICU); a Pediatric Intensive Care Unit (PICU); Radiology; a Delivery room; inpatient and outpatient rooms; a Polyclinic; a Pharmacy; Hemodialysis and a Laboratory. This hospital was chosen because, being a newly established hospital, it is still looking for an effective and efficient form or design of 
services which can calculate the price of services per patient more precisely.

\section{Findings and Results}

This research was conducted in the midst of the Covid-19 Pandemic, so the data collection process was carried out online in the context of physical distancing. In accordance with the agreement with the hospital management, the scope of this research is limited as follows: (a) Operational scope: Dental Polyclinic (b) Time: the period of three months (June, July and August 2020) (c) Data: - Part of the Income and Expense Report of the Dental polyclinic operational Process.

\section{Dental Poly Operational Process}

The research was conducted on a dental polyclinic, where the operational process consists of 4 main processes, namely: (a) Patient registration. (b) Patient examination. (c) Payment. (d) Pharmacy. The operational process for dental poly services can be seen in the following flow chart (Appendix 1):

-Flowchart (Appendix 1)-

\section{Hospital Operational Efficiency Level}

To answer the formulation of the first problem in this research, in relation to the analysis of the operational efficiency of the hospital, the following data were collected regarding the operational efficiency for 3 months:

Table 1: Summary of Financial Data Flow at Hospital X in Depok Division - Dental Polyclinic From June to August 2020

\begin{tabular}{|c|c|c|}
\hline Information & & Amount \\
\hline Dental Poly Income June-August & & Rp $195,410,169$ \\
\hline \multicolumn{3}{|l|}{ Cost : } \\
\hline The purchase price of drugs, June to August & Rp $\quad 1,862,072$ & \\
\hline Dental Poly Vendor Bill, June to August & Rp $\quad 2,825,000$ & \\
\hline Dentist nurse's salary & Rp $\quad 16,473,723$ & \\
\hline Doctor's salary & Rp $71,793,215$ & \\
\hline Doctor consumption & 370,807 & \\
\hline Depreciation of Tools at Dental Clinic & $\mathrm{Rp} \quad 8,578,231$ & \\
\hline Depreciation of Panoramic Tools & Rp $32,031,250$ & \\
\hline The number of costs & & Rp 133,934,299 \\
\hline $\begin{array}{l}\text { Profit or Loss of Dental Polyclinic, June to } \\
\text { August }\end{array}$ & & Rp $\quad 61,475,870$ \\
\hline
\end{tabular}

Source: internal hospital X in Depok.

From this data, the level of operational efficiency will be calculated using the following formula:

$$
\text { Efficiency }=\frac{\text { Total Input }}{\text { Total Output }}
$$


If this efficiency value is getting closer to 1 , the hospital could be said to have carried out its operational activities effectively.

\section{Planning Stage}

This stage is the first stage in an ecoefficient analysis using Material Flow Cost Accounting (MFCA). This planning stage consists of:

a. Determination of product or service targets

In accordance with the results of discussions with the management of Hospital $X$ in Depok, the planning stage begins with determining the target product/service which is the scope of the research. In this research, the target of services to be analyzed using MFCA is outpatient services at the dental polyclinic. The choice of this dental polyclinic was intended because the procedures and operational scope were simpler than other services.
b. Determination of MFCA Limits and quantity centers

In accordance with the MFCA concept, it is necessary to determine the quantity center in implementing a good MFCA. A quantity Center is a unit within the organization which involves input, process, and output. Output, in one quantity center, can consist of a successful product (positive product) and the rest of the material/waste (negative product/waste). For a brief description of the scope of the service target in relation to input, process and output, Figure 1 shows the dental poly service process as follows:

\section{Dental Polyclinic Service Process}

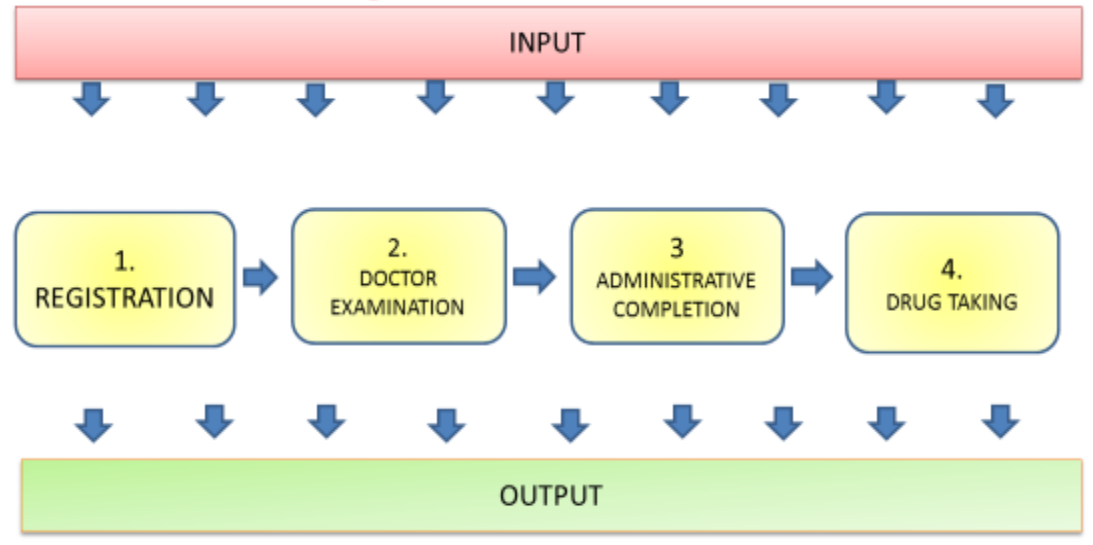

Figure 1: Service Target MFCA of Hospital X

Source: Internal Data of Hospital X in Depok

c. Specifying the time period

Based on the agreement with the management of hospital $\mathrm{X}$, it was agreed that the focus of this research is the operational process of the hospital for three months, from June to August 2020. d. Efficiency analysis using Conventional Production Management (CPM)

The efficiency analysis of RS X Depok with conventional methods is as follows: 


Efficiency $=\frac{\text { Total input }}{\text { Total output }}$
Efficiency $=\frac{\operatorname{Rp~} 133,934,299}{\operatorname{Rp~} 195,410,169}$
$=68,54 \%$

e. Developing a model of material flow per center quantity

In the previous section, the quantity center, being the focus of the research has been determined. At this stage, it is used to compile a material flow per quantity model. This stage of the research begins by identifying the activities that occur at each quantity center in details as follows:

\section{Quantity Center's Registration}

Quantity Center (QC) registration is the beginning of the service activities at the dental polyclinic of hospital X in Depok. The activity carried out is for patients (either new or old) to register for a service that day at the registration counter by bringing their medical card (old patient) or KTP/personal data (new patient) and insurance card (if any).

2. Quantity Center's Doctor Examination

The doctor's examination is the second QC in the dental polyclinic. This activity starts from the moment the patient reregisters or reports to the nurse on duty to record complaints or to be examined by the doctor for treatment. The nurse records the patient's temperature and records the answers to his/her complaints. Then, the patient waits to be called into the doctor's examination room. After the patient has a turn to enter the examination room, the activity that occurs next is that the doctor conducts an interview with the patient, asking about his/ her complaints, recording information in a medical record book, and performing an examination. The need for drugs and medical equipment depends on the patient's case. After the examination, the doctor refers the patient to supporting services (only if needed) such as laboratories, radiology (photo panoramic), and so on. In the next step, the doctor writes down the examination note in the medical record book, provides a prescription note (if any), and writes down all examination steps and drugs or treatments advised on the treatment form as a way for charging medical expenses or financial administration settlement by the patient. The doctor also provides a note for next visit (if needed).

3. Quantity Center's Administrative Completion

Further activities are carried out at QC completion of procedures, starting from the patient queuing at the cashier with documents for making payments. As per the queue, the cashier serves the patient when it is his/her turn. The patient shows documents such as a completed medical treatment form, drug prescription, etc. Then, the cashier checks the information system, making some ratings and calculations. The patient then pays according to the cashier's bill, either via cash or debit and then receives a proof of payment with the drug prescription to take the drug from the pharmacy.

\section{Quantity Center's Drug Taking}

The activities that occur in QC for drug taking are as follows: (1) the patient goes to the pharmacy unit with evidence of drug settlement and a prescription from the doctor; (2) pharmacists process drug-taking; and (3) a verification of the patient's data is carried out and drugs are submitted. Furthermore, after the patient receives the medicine, the dental clinic service 
process is completed and the patient goes home.
The activities of each QC, if described, are as follows:

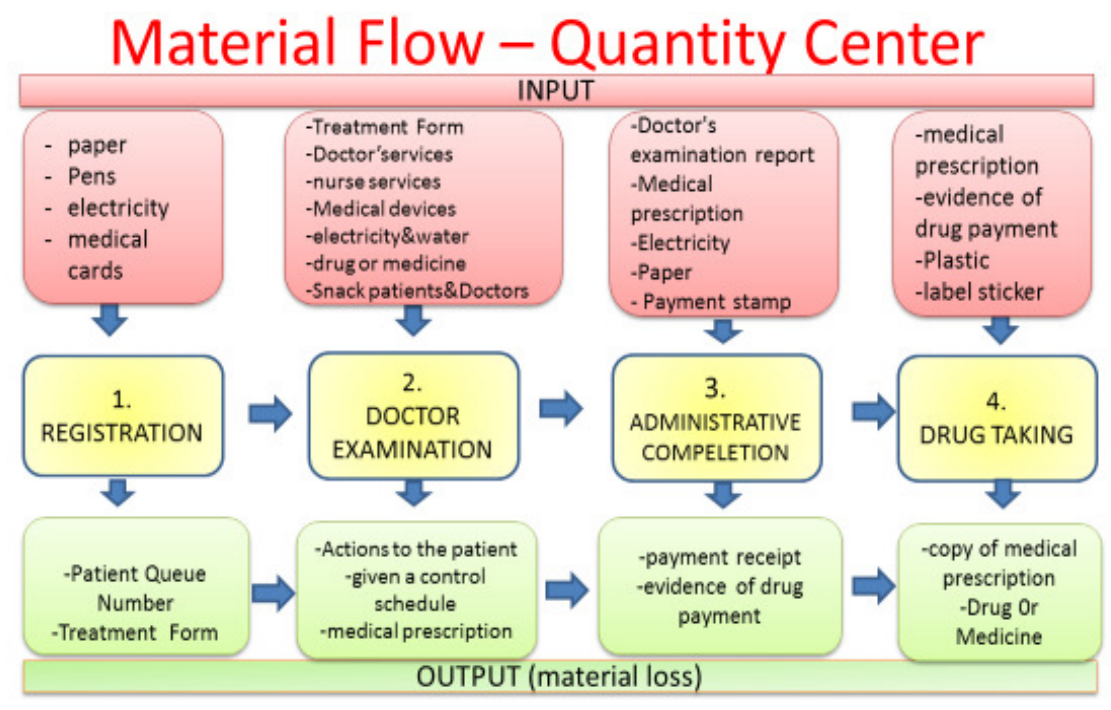

Figure 2: Quantity Center MFCA of Hospital X

Source: Internal Data of Hospital X Depok

The next step, after identifying the activities of each QC, the material flow (material flow) is identified. This will be presented in the next section.

\section{Implementation Stage:}

The inputs and outputs based on the material flow model per quantity center are as follows:

\section{Quantity Center's Registration}

Inputs needed in QC are papers (form) for registration (for new patients), a ballpoint for writing, electricity for application system resources on the computer, and blank medical card forms to print new patients' identities. The outputs of the registration $\mathrm{QC}$ are the queue numbers and the patients' treatment forms.

2. Quantity Center's Doctor
Inputs needed in this activity are medical treatment forms, doctor services, nursing services, medical devices, electricity, water, equipment (medicine, etc.), doctor snacks, and patient snacks. The outputs produced in this activity are actions to patients, control schedules, drug prescriptions, and doctor's examination reports/treatment forms that contain details of the doctor's actions (bills).

3. Quantity Center's Administrative Completion

Inputs needed in this activity are the doctor's examination reports, drug prescriptions, electricity, medical treatment receipt papers, and payment stamps. The outputs produced in this activity are receipts for payment of examination fees, proof of drug settlement and drug prescriptions. 
4. Quantity Center's Drug Taking

Inputs required in this activity are drug prescriptions, proof of payment of drug payments, plastic wrapping to wrap drugs, and label stickers to record drug information. The outputs produced in this activity are a copy of the drug prescription and the drug that was submitted.

b. Determination of the tie compound This stage of the research analyzes the ties in the MFCA or tie compound as a cycle of the relationship between input, process and output, as described in Figure 6.

\section{Material Flow - Tie Compound}

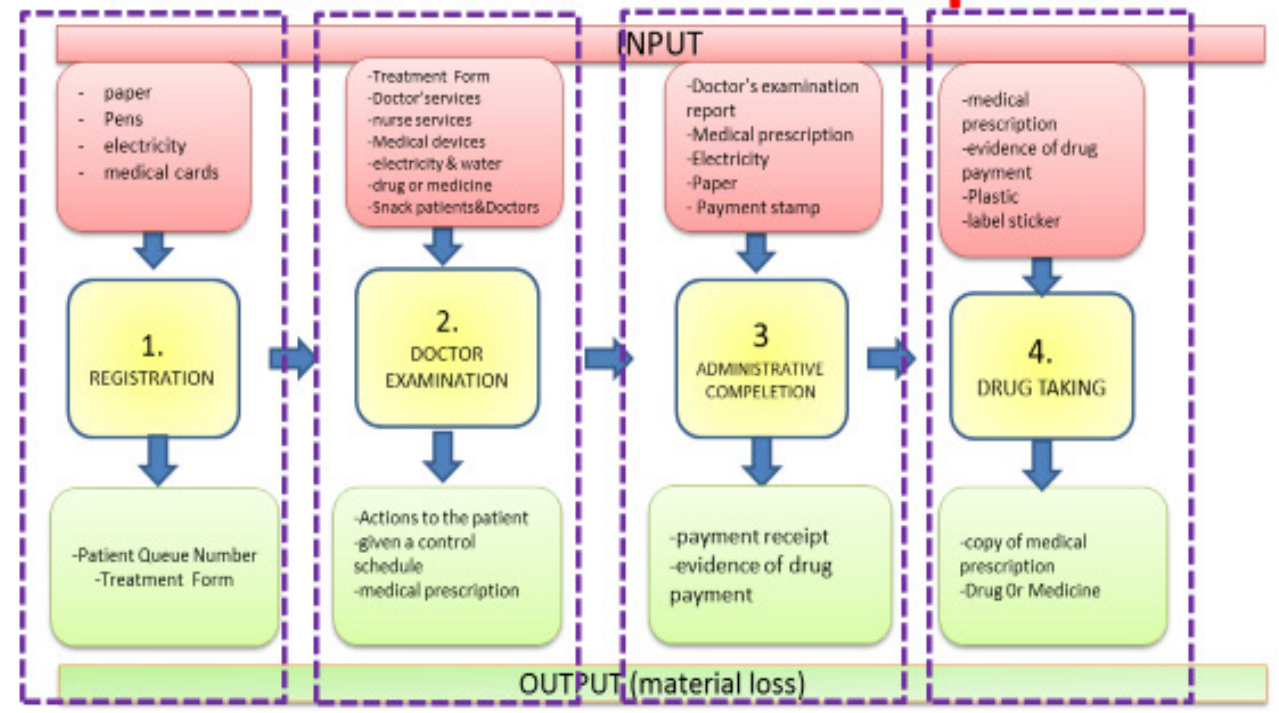

Figure 3: Tie Compounds of Hospital X

Source: Internal Data of Hospital X Depok

In Figure 3 above, the tie compound at hospital X in Depok, which is the object of the research, consists of 4 tie-compounds, namely:

1. Tie-Compound Registration.

2. Tie-Compound Doctor Examination.

3. Tie-Compound Administrative Completion.

4. Tie-Compound Drug Taking.

These four tie-compounds form the basis of the MFCA analysis.

c. Evaluation and filtering of material balances and calculating the inputoutput in monetary units

The next two steps in this research are presented in one section. Evaluation and filtering of material balances are carried out by the finance department by collecting supporting data for financial statements, namely a list of material balances. This research was conducted from June 2020, so that the material balance needed is the balance at the end of May 2020. Furthermore, the research is continued by calculating the input-output that is included in the quantity center in the monetary unit.

d. Making the cost implication (attaching the real nominal amount to the quantity center according to the accrual data)

This step is carried out by identifying the positive and negative products of each quantity center. A positive product is the number of resources that are 
consumed into service components produced or enjoyed by dental clinic patients. Negative products are tracing the resources that are actually wasted, as these resources are not consumed in real terms to produce services. Some resource components are not available with accurate data because they are at the hospital level (not at the Poly level). However, from the explanation of the hospital's financial staff, a logical assumption is made.

e. Calculating waste or loss (per unit and per rupiah)

Waste or loss is identified from the search results for each quantity center and from an explanation from the hospital's financial staff. Waste or loss in the manufacturing industry can be easily identified even by using conventional cost calculation methods. However, this is not the case with the service industry. Waste or loss cannot be identified if the company uses conventional cost calculations.

The results of data collection and identification of inputs and, outputs (positive products and negative products) both in quantity units and monetary units in each Hospital $X$ quantity center are presented in Table 2 . f. Analysis and interpretation of MFCA results

The implementation of MFCA in the dental polyclinic at Hospital X in Depok produces Material Flow data which is presented in Table 2. The operational process in the dental polyclinic is simpler than other polyclinics. The efficiency level of the dental polyclinic at hospital X is $68.54 \%$. This means that the resources consumed by the dentist in 3 months are $68.54 \%$, contributing to the formation of the income.

The eco-efficient analysis is implemented as part of a company's effort to pay attention to the impact of operational activities on environmental sustainability. Kondo \& Nakamura (2005) explain that waste management and recycling procedures are companies' efforts to achieve ecoefficiency by comparing between inputs and outputs in the operational process. Table 2 shows the operational or service process in the dental polyclinic by tracing material flow (MFCA). From the identification process per quantity center, in a period of 3 months (June to August 2020), negative products were obtained, which had never been previously detected by hospital X. 
Table 2: Material Flow in monetary units

\begin{tabular}{|c|c|c|c|c|c|c|c|c|c|c|c|}
\hline $\begin{array}{l}\text { Flow } \\
\text { No. }\end{array}$ & Process & Input & $\begin{array}{c}\text { Input } \\
\text { quantity }\end{array}$ & & $\begin{array}{l}\text { Input Cost } \\
\text { (IDR) }\end{array}$ & (+) products & \begin{tabular}{|c|}
$\begin{array}{c}\text { Persentage } \\
(+) \text { products }\end{array}$ \\
\end{tabular} & $\begin{array}{c}\text { Cost (+) } \\
\text { products (IDR) }\end{array}$ & (-) products & \begin{tabular}{|l|} 
Persentage \\
(-) products \\
\end{tabular} & $\begin{array}{c}\text { Cost (-) } \\
\text { products (IDR) } \\
\text { pods }\end{array}$ \\
\hline \multirow[t]{4}{*}{1} & Registration & Paper & 15 & rim & 675,000 & $\begin{array}{l}\text { Registration } \\
\text { proof }\end{array}$ & $93 \%$ & 627,750 & Paper Scrap & $7 \%$ & 47,250 \\
\hline & & Ballpoint & 5 & box & 130,000 & $\begin{array}{l}\text { registration } \\
\text { form }\end{array}$ & $100 \%$ & 130,000 & & $0 \%$ & - \\
\hline & & Energy & 2,920 & kwh & $4,218,750$ & Energy & $80 \%$ & $3,375,000$ & \begin{tabular}{|l} 
Energy excess \\
usage
\end{tabular} & $20 \%$ & 843,750 \\
\hline & & Medical Card & 220 & Patien & $5,225,418$ & Medical card & $95 \%$ & $5,225,418$ & $\begin{array}{l}\text { Medical card } \\
\text { scrab }\end{array}$ & $5 \%$ & 261,271 \\
\hline \multirow[t]{8}{*}{2} & Doctor's examination & Doctor's fee & 209 & Patien & $19,895,000$ & Doctor's fee & $100 \%$ & $19,895,000$ & & $0 \%$ & - \\
\hline & & Nurse's fee & 209 & Patien & $16,473,723$ & Nurse's fee & $100 \%$ & $16,473,723$ & & $0 \%$ & \\
\hline & & Medical tools & 59 & Uses & $8,578,231$ & Medical tools & $94 \%$ & $8,578,231$ & Medical tools & $6 \%$ & 536,139 \\
\hline & & Energy & 2,920 & kwh & $4,218,750$ & Energy & $75 \%$ & $3,164,063$ & $\begin{array}{l}\begin{array}{l}\text { Energy excess } \\
\text { usage }\end{array} \\
\end{array}$ & $25 \%$ & $1,054,688$ \\
\hline & & Water & 500 & $\mathrm{~m} 3$ & $6,500,000$ & - & $0 \%$ & & Water waste & $100 \%$ & $6,500,000$ \\
\hline & & Supplies (medcines,etc) & 242 & pcs & $1,862,072$ & \begin{tabular}{|l|}
$\begin{array}{l}\text { Supplies } \\
\text { (medcines,etc) }\end{array}$ \\
\end{tabular} & $90 \%$ & $1,862,072$ & \begin{tabular}{|l|} 
Scrap of \\
supplies \\
(medicine, etc)
\end{tabular} & $10 \%$ & 186,207 \\
\hline & & $\begin{array}{l}\text { Doctor's dan patien's } \\
\text { snack }\end{array}$ & 3,420 & pcs & $5,780,200$ & \begin{tabular}{|l|}
$\begin{array}{l}\text { Doctor's dan } \\
\text { patien's snack }\end{array}$ \\
\end{tabular} & $98 \%$ & $5,780,200$ & Scrab of Snack & $2 \%$ & 115,604 \\
\hline & & Panoramic & 24 & uses & $32,031,250$ & $\begin{array}{l}\text { Foto } \\
\text { panoramic }\end{array}$ & $100 \%$ & $32,031,250$ & & $0 \%$ & - \\
\hline \multirow[t]{5}{*}{3} & Administration & Medical record & 209 & $\begin{array}{l}\text { patien } \\
t\end{array}$ & $9,770,508$ & $\begin{array}{l}\text { Medical } \\
\text { record }\end{array}$ & $100 \%$ & $9,770,508$ & & & - \\
\hline & & Medicine prescription & 168 & sheet & $1,108,800$ & \begin{tabular}{|l} 
Medicine \\
prescription \\
payment \\
receipt
\end{tabular} & $100 \%$ & $1,108,800$ & \begin{tabular}{|l} 
Medicine \\
prescription \\
payment \\
receipt
\end{tabular} & $0 \%$ & \\
\hline & & Energy & 2,920 & kwh & $4,218,750$ & Energy & $80 \%$ & $3,375,000$ & $\begin{array}{l}\text { Energy excess } \\
\text { usage }\end{array}$ & $20 \%$ & 843,750 \\
\hline & & Paper & 9 & rim & 405,000 & \begin{tabular}{|l|} 
Payment \\
Receipt
\end{tabular} & $95 \%$ & 384,750 & $\begin{array}{l}\text { scrap payment } \\
\text { receipt }\end{array}$ & $5 \%$ & 20,250 \\
\hline & & Paid Stamp & 209 & uses & $1,045,000$ & Paid Stamp & $100 \%$ & $1,045,000$ & Paid Stamp & & - \\
\hline \multirow[t]{7}{*}{4} & \begin{tabular}{|l} 
Pharmacy \\
\end{tabular} & Medicine prescription & 168 & sheet & $1,108,800$ & $\begin{array}{l}\text { Copy } \\
\text { Medicine } \\
\text { prescription }\end{array}$ & $100 \%$ & $1,108,800$ & & & - \\
\hline & & $\begin{array}{l}\text { Medicine payment } \\
\text { receipt }\end{array}$ & 168 & sheet & 504,000 & \begin{tabular}{|l} 
Medicine \\
payment \\
receipt
\end{tabular} & $100 \%$ & 504,000 & & & \\
\hline & & Plastic & 450 & pcs & $4,500,000$ & $\begin{array}{l}\text { Medicine } \\
\text { Packaging }\end{array}$ & $95 \%$ & $4,275,000$ & Plastic scrap & $5 \%$ & 225,000 \\
\hline & & Label Sticker & 450 & pcs & 450,000 & Label Sticker & $95 \%$ & 427,500 & $\begin{array}{l}\text { Label Sticker } \\
\text { Scrap }\end{array}$ & $5 \%$ & 22,500 \\
\hline & & Energy & 2,920 & kwh & $4,218,750$ & listrik & $80 \%$ & $3,375,000$ & $\begin{array}{l}\text { Energy excess } \\
\text { usage }\end{array}$ & $20 \%$ & 843,750 \\
\hline & & Water & 78.18 & $\mathrm{~m} 3$ & $1,016,297$ & 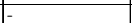 & $0 \%$ & - & Water waste & $100 \%$ & $1,016,297$ \\
\hline & TOTAL & & & & $133,934,299.6$ & & & $122,517,065.0$ & & & $12,516,456.2$ \\
\hline
\end{tabular}

Source: processed data

From the analysis of inputs and outputs, especially the identification of positive and negative products, Table 2 shows that the input used by the hospital for 3 months, namely Rp. 133,934,299, did not entirely produce positive products, but there was a few percent that became waste/lost/damaged, according to the MFCA concept. This is called a negative product (loss). A total of Rp. 122,517,065 was a positive product or was actually consumed as services to patients during the months from June to August 2020. The number of positive products, if the percentage is calculated, is $91 \%$ of the total input/resources/materials consumed by the dental clinic during the production process of its services. The research results show that Rp. 12,516,456 is a material that becomes a negative product, or according to this MFCA concept, it is called waste/lost/damaged. If calculated, the percentage of waste/loss is $9 \%$ (see Table 2) of the total material that goes into the production process of RS X dental services for 3 months, which was not previously detected by the management of X Hospital. Even though, only $9 \%$ of the total material/resources consumed are waste/loss, this amount is very material if it is related to the cumulative impact of environmental damage that may be caused, especially since the waste generated by the health service industry requires more careful attention and handling. 
Table 3: Comparison of Input Material Efficiency using Conventional Methods and MFCA

\begin{tabular}{|l|c|c|c|}
\hline & INPUT (IDR) & \multicolumn{2}{|c|}{ OUTPUT (IDR) } \\
\hline & & PRODUCT & MATERIAL LOSS \\
\hline Before MFCA & $133,934,299$ & $133,934,299$ & - \\
\hline & $100 \%$ & $100 \%$ & $0 \%$ \\
\hline After MFCA & $133,934,299$ & $122,517,065$ & $12,516,456$ \\
\hline & $100 \%$ & $91 \%$ & $9 \%$ \\
\hline
\end{tabular}

Source: internal data processed

The analysis during this 3 -month period is an illustration that by tracing the flow of material as in the MFCA concept, hospital X is able to reduce resource consumption which has an impact not only on saving the hospital's expenses but also on reducing material costs from IDR $133,934,299$ to 122,517. 065 (save 9\%). However, the expected benefit, in the long run, is the achievement of eco-efficiency so that it can realize the operational sustainability of the hospital. Ecoefficiency is an increase in efficiency due to efforts aimed at minimizing the level of pollution to the environment.

The results of this research are consistent with those of Christ \& Burritt (2015); Tajelawi \& Garbharran (2015) by using Material Flow Cost Accounting (MFCA) so that it can help companies/organizations create eco-efficiency conditions. This is because MFCA is indeed a tool created to encourage the achievement of ecoefficiency in organizations allowing organizations to focus on reducing material use and improving the company's economic performance. MFCA improves transparency in material flows and energy consumption in companies, which can be a helpful tool for management (Dierkes \& Siepelmeyer, 2019; Huang et al., 2019). MFCA is the best solution where financial performance and economic performance can be synergized for continuous improvement.

\section{Conclusion}

This research intends to analyze the efficiency level of Hospital X's operation using a conventional method and Material Flow of Cost Accounting (MFCA). The research was conducted for three months and showed that the current hospital's efficiency level was $68.54 \%$, meaning that the hospital's efficiency level was quite high. However, with the conventional method, the hospital does not know how much inefficiency is related to the environment or pollution caused by the hospital's operational activities.

The implementation of MFCA resulted in that the hospital's operational activities for three months led to a negative product of $9 \%$ of the total material input or Rp. 12,516,456, which was not previously detected by conventional methods. Compared to the manufacturing industry sector, the efficiency level of the health care service industry is lower, because the MFCA concept is more suitable in material waste reduction and more applicable in the manufacturing sector. However, the results of the analysis of material flow tracing using this MFCA have the main benefit of minimizing waste and energy consumption, thereby saving the environment from damage, and thus realizing the sustainable operation of RS X. This means that if MFCA is applied continuously, hospital $\mathrm{X}$ will not only save expenses but can also achieve eco-efficiency and realize continues improvement so that, in the long-term, operational sustainability can be achieved.

\section{Limitations and Suggestions}

This research has several limitations related to data access. The research was conducted during the Covid 19 pandemic, so the research team could not directly visit the research object, and hence the communication and coordination with the hospital management were carried out online with limited intensity and some limited data accessed by researchers. Another limitation is the amount of data obtained. The hospital management limits the data to only three months and only on the dental unit or clinic, which made it difficult to trace some data related to operational costs at the central level. Assumption and analogy are used in data analysis and discussion based on the hospital real case and literatures. The limited theoretical and empirical 
literature on the application of MFCA in the service sector limits the analysis of the results.

Suggestions that can be recommended for further research are related to using public hospital data sources (financial reports are available) and using proxy measures with secondary data. Future research can further explore MFCA in manufacturing sector companies because the characteristics of this sector are more relevant concerning the flow of material which is the focus of MFCA. Thus, it can be seen, in more detail, to what extent MFCA can encourage eco-efficiency.

\section{References}

- Barney, J. (1991). Firm Resources and Sustained Competitive Advantage. Journal of Management. Vol. 17. No.1, pp. $99-120$.

- Blewitt, J. (2015). Understanding Sustainable Development. Second Edition. New York: Routledge.

- $\quad$ Burritt, R.L., Hahn, T., and Schaltegger, S. (2002). Toward a Comprehensive Framework for Environmental Management Accounting - Links Between Business Actors and EMA Tools. Australian Accounting Review. Vol. 12. No. 2, pp. $39-$ 50 .

- $\quad$ Christ., K.L., and Burritt, R.L. (2015). Review Material flow cost accounting: a review and agenda for future research. Journal of Cleaner Production. Vol. 108., pp. 1378 1389.

- Dierkes, S., \& Siepelmeyer, D. (2019). Production and cost theory-based material flow cost accounting. Journal of Cleaner Production. No. 235., pp. 483 - 492. DOI: 10.1016/j.jclepro.2019.06.212

- Clulow, V. (2007). The resource-based view and value: the customer-based view of the firm. Journal of European Industrial Training. Vol. 31. No. 1, pp. 19 - 35.

- Kondo, Y., \& Nakamura, S. (2005). Waste
Input-Output Linear Programming Model with its Application to Eco-Efficiency Analysis. Economic Systems Research. Vol. 17, No. 4, 393 - 408.

- Huang, S., Chiu, A., Chao, P., \& Wang, Ni. (2019). The application of material flow cost accounting in waste reduction. Sustainability. Vol. 11., No. 5, pp.1 - 27. https://doi.org/10.3390/su11051270

- Madein, A., Sholihin, M. (2015). The impact of social and environmental information on managers' decisions: Experimental evidence from Indonesia. Asian Review of Accounting. Vol. 23. No. 2, pp. $156-169$.

- Pfeffer, J., Salancik, G. R. (1978). The External Control of Organizations: A Resource Dependence Perspective. New York: Harper \& Row.

- Prasetiyo, H. (2016). G-20 Leader's Communique Hangzhou Summit 2016: Negara G-20 Dalam Memandang Sustainable Development Goals. http://infid.org. Accessed on 8 June 2017.

- Qian, W., Burritt, R.L. (2010). Environmental management accounting in local government, A case of waste management. Accounting, Auditing, and Accountability Journal. Vol. 24. No. 1, pp. 93 $-128$.

- Tajelawi, O., \& Garbharran, H. L. (2015). MFCA-An-Environmental-ManagementAccounting-Technique-for-OptimalResource-Efficiency-in-ProductionProcesses. World Academy of Science, Engineering and Technology International Journal of Mechanical and Industrial Engineering. Vol. 9. No. 11, pp. 3765 - 3770.

- Tachikawa, H. (2015). Material Flow Cost Accounting (MFCA): Concepts, Practices, and Impacts. Workshop on Material Flow of Cost Accounting as Part of Accounting and Productivity. Jakarta: ASEAN Productivity Organization and Directorate General of Training and Productivity Ministry of Manpower. 
Appendix 1. Flowchart of Dental Polyclinic Services Hospital X Depok

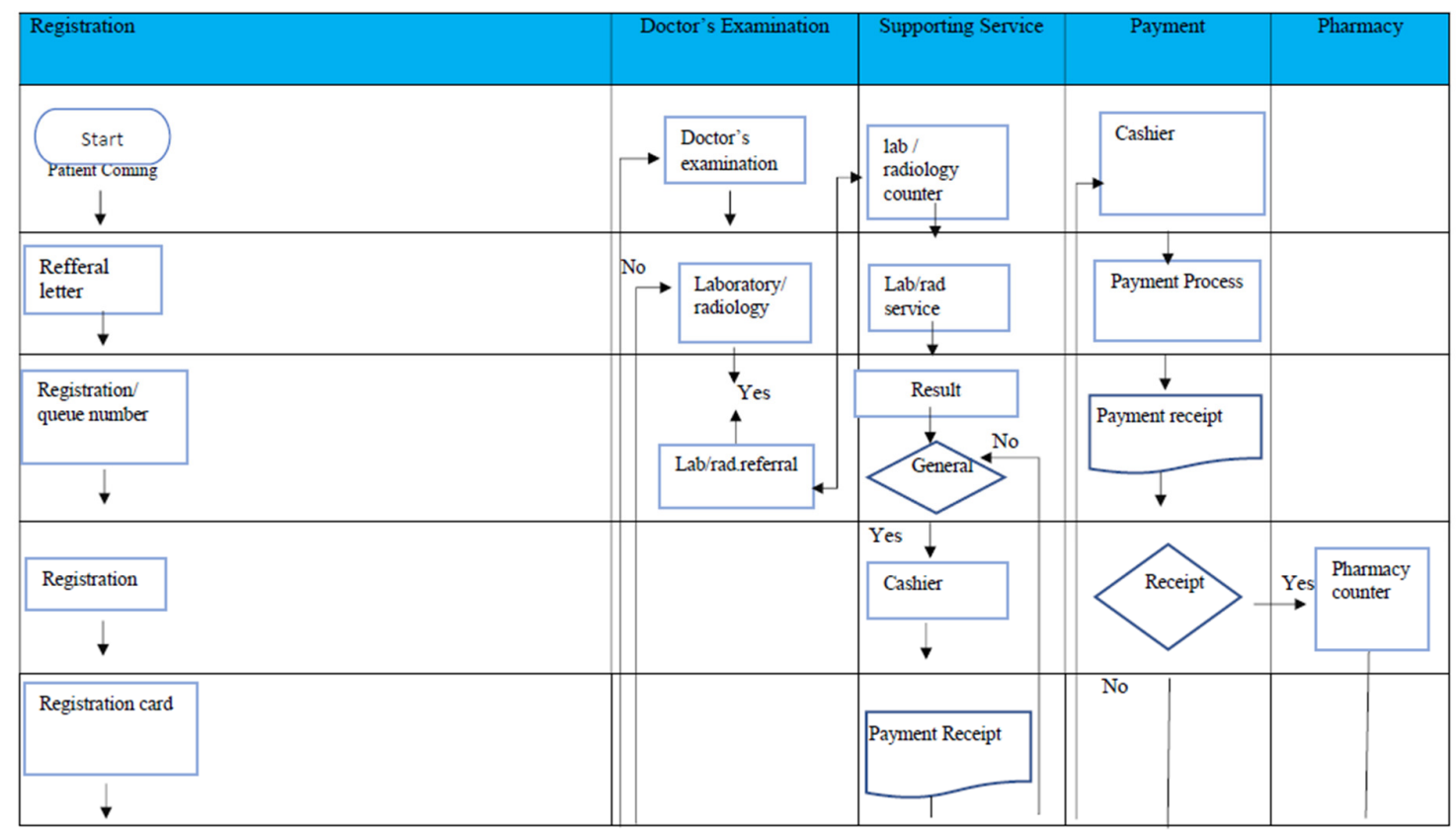

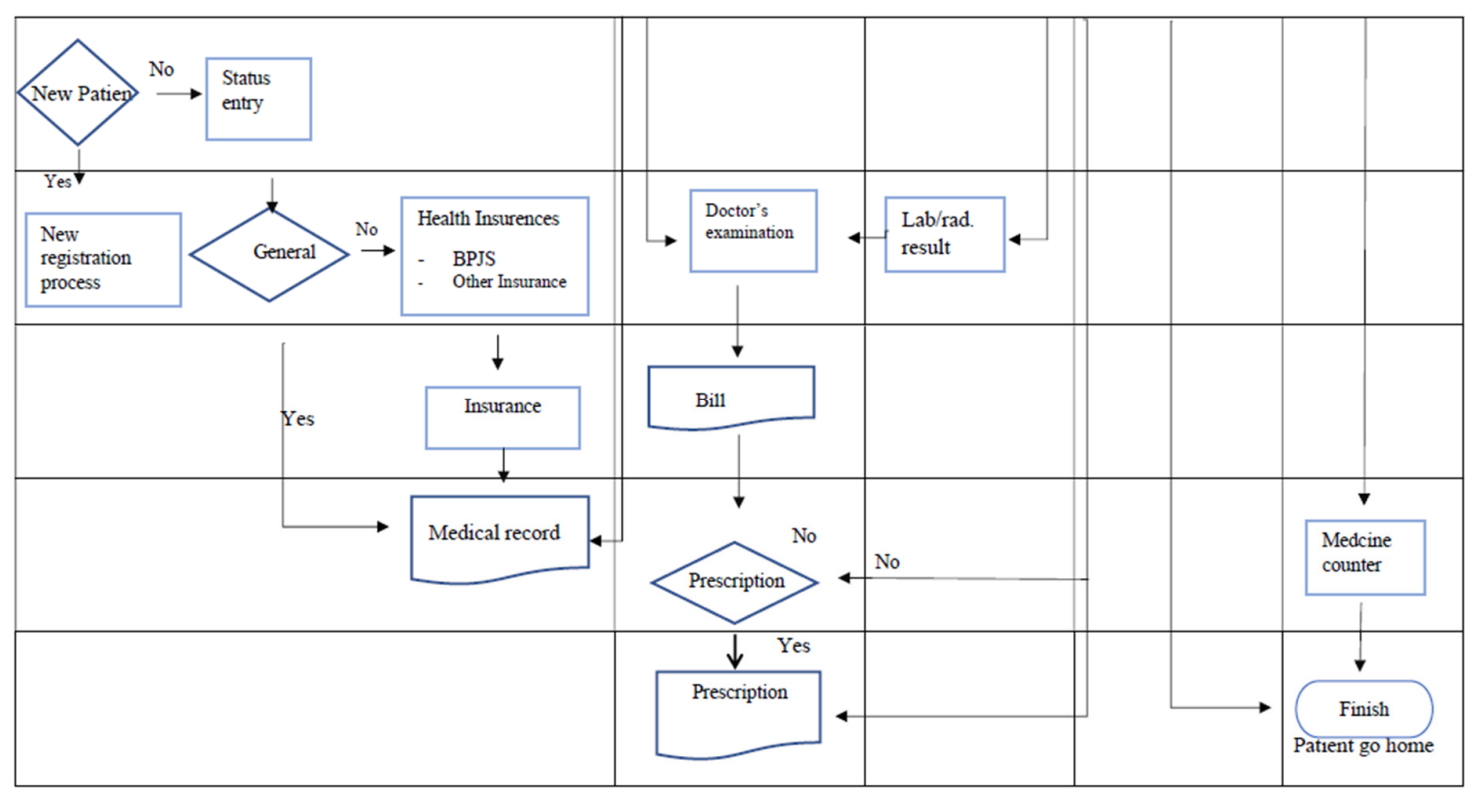

Source: Data Processed 